\title{
La Prensa Brasileña y sus "Cruzadas Morales": Un Análisis de los Casos del Segundo Gobierno de Getúlio Vargas y el Primer Gobierno de Lula da Silva
}

\author{
Ariel Goldstein \\ Universidad de Buenos Aires (UBA), Buenos Aires, Argentina. E-mail: \\ arielgoldstein@hotmail.com
}

\section{INTRODUCCIÓN: LA PRENSA BRASILEÑA Y SUS “CRUZADAS MORALES"}

F ste artículo aborda los encuadres y discursos de dos periódicos, $O$

E Estado de S. Paulo y O Globo, durante dos gobiernos caracterizados por una dirección política basada en liderazgos populares: el segundo gobierno de Getúlio Vargas (1951-1954) y el primer gobierno de Lula (2003-2006). Especialmente, el trabajo se centrará en la importancia que adquirió en ambos períodos el discurso que hacía referencia a cuestiones morales como expresión de las posiciones asumidas por estos periódicos, aquello que podemos denominar como las "cruzadas morales".

Las "cruzadas morales" serán identificadas en función de lo que señalamos como una colonización del discurso sobre los asuntos públicos en función de la distinción entre políticos "honestos" y "corruptos". Entendemos que la instrumentación de la moralidad por parte de la prensa brasileña, en distintos períodos históricos, ha tenido por función naturalizar el orden social en el país. De este modo, sostendremos que la moralización de la política (Rubim, 2006) se revelaría en ambos períodos como una condición necesaria para la naturalización del orden social por parte de estos medios de prensa ${ }^{1}$.

Un papel organizador en nuestro trabajo lo cumplirá la teoría de los encuadres desarrollada por Gamson y Modigliani (1989). La teoría del framing define un encuadre como una idea central que organiza y

DADOS - Revista de Ciências Sociais, Rio de Janeiro, vol. 60, no2, 2017, pp. 395 a 435.

http://dx.doi.org/10.1590/001152582017124 
provee sentido a los acontecimientos, defendida por grupos sociales que pretenden ejercer influencia en la esfera pública, sugiriendo "qué es un tema". A partir de esta idea se seleccionan y tornan relevantes determinados aspectos de una realidad para promover definiciones, causas y consecuencias de los eventos, y apelar a principios para promover cursos de acción (Entman, 1993). Gamson y Modigliani conciben el discurso de los medios en función de una serie de paquetes interpretativos que proveen significado a determinados temas. Cada paquete tiene una estructura interna, y en su centro hay una idea central organizadora, o encuadre, para dar sentido a los eventos relevantes (Gamson y Modigliani, 1989).

También utilizaremos la perspectiva del análisis del discurso de Verón (1987), quien define las "estrategias" enunciativas de los actores políticos como constituidas por un "núcleo" invariante y un sistema de variaciones. Esta orientación supone la identificación del dispositivo de enunciación de los discursos, conformado por la relación establecida entre el enunciador y el destinatario. Específicamente en los discursos políticos, las relaciones entre ambos sujetos de enunciación adquieren un carácter polémico, esto es, de enfrentamiento: el discurso está habitado por un Otro negativo (contradestinatario), en contraposición al cual el enunciador se constituirá. A su vez, existen dos tipos más de destinatarios, el prodestinatario (con el cual un enunciador comparte ideas, valores y creencias) y el paradestinatario (al cual el enunciador intentará persuadir, dado que este destinatario no posee una posición definida).

Finalmente, las formulaciones de Barthes (2004) nos permitirán alcanzar un refinamiento en el análisis de las construcciones producidas por estos periódicos. En este sentido, el autor identifica al mito como un sistema de comunicación, un sistema semiológico segundo que, produciendo una deformación del sentido, convierte a la historia de la luchas de intereses en naturaleza, consigue abolir la complejidad de los actos humanos para otorgarle la simplicidad de las esencias, así como organiza un mundo sin contradicciones.

A nivel metodológico, para el estudio de los titulares, editoriales y columnas de opinión, hemos definido, como señala Porto (2002), la conveniencia de adoptar un enfoque que combine un análisis tanto cuantitativo como cualitativo, para reforzar la contrastación de los datos de nuestra investigación. Sin embargo, destacamos que en este caso el análisis cuantitativo de clasificación de editoriales tiene como fin únicamente oficiar de orientador para la realización del análisis cualitativo, central para este trabajo. 
A partir del relevamiento, se propone la clasificación de los editoriales en encuadres de acuerdo a su temática dominante (Gamson y Modigliani, 1989; Miguel y Coutinho, 2007). Posteriormente, se adoptará un análisis de los discursos del período, en base a los lineamientos metodológicos de la teoría de los discursos sociales de Verón (1987) y los desarrollos sobre las ideologías políticas de Ansart (1983) y Barthes (2004).

Se definió abordar ambos períodos en función de determinadas coyunturas críticas, seleccionadas considerando que durante las mismas se desarrollaron las principales tensiones y alineamientos asumidos por los actores políticos. Es por ello que el análisis del período correspondiente al segundo gobierno de Vargas fue delimitado en función de las siguientes coyunturas:

1) Desde la asunción del presidente hasta el discurso del primero de mayo (1951), que abarcaría los primeros 100 días del gobierno, del 31/1/1951 hasta el 10/5/1951.

2) El caso Última Hora y la estadía de João Goulart al frente del Ministerio de Trabajo (1953-1954), que abarcó 234 días, del 20 / 05 / 1953 al $22 / 02 / 1954^{2}$.

3) La coyuntura de agosto de 1954, el suicidio de Vargas y la asunción de Café Filho (1954), que abarcó 92 días, del 01/06/1954 al $31 / 08 / 1954$.

Los tres períodos de análisis durante el segundo gobierno de Vargas abarcaron 426 días. Por otra parte, para el primer gobierno de Lula fueron seleccionadas estas tres coyunturas:

1) La reforma de la jubilación (2003), del 01/05/2003 al 27/11/2003, 211 días.

2) El escándalo del "mensalão" (2005), del 14/05/2005 al 09/11/2005, 180 días.

3) La campaña electoral y las elecciones presidenciales de 2006 (2006), 01/05/2006 al 29/10/2006, 182 días².$^{2}$

Con respecto al período de Vargas, fueron leídos 1452 editoriales de $O$ Estado de S. Paulo (O ESP), y para la cuestión de la "cruzada moral", fueron analizados en el período Vargas 65 editoriales de este periódico. En el caso de $O$ Globo, fueron leídos 499 editoriales, de los cuales se seleccionaron para el análisis de la "cruzada moral" siete editoriales.

DADOS - Revista de Ciências Sociais, Rio de Janeiro, vol. 60, nº 2, 2017 


\section{Ariel Goldstein}

Con respecto al período de Lula, fueron leídos 1716 editoriales de $O$ $E S P$, de los cuales se seleccionaron para el análisis de la "cruzada moral" 81 editoriales. Para O Globo, fueron leídos 925, de los cuales se seleccionaron para el análisis 60.

Los estudios sobre medios y política en Brasil constituyen un campo que ha tenido un gran desarrollo en los últimos años. En este sentido, podemos mencionar trabajos importantes sobre el rol de la prensa durante los gobiernos de Vargas tales como Carvalho (2012), Goulart (2007), Capelato (2013), Biroli (2004), Abreu y Lattman-Weltman (1994). También resulta relevante considerar los trabajos más actuales sobre los vínculos del PT en el gobierno con los medios de prensa como el testimonio de Kotscho (2006), y los trabajos de Porto (2012), Kucinski (1998; 2007), Lima (2006), Azevedo (2009), Rubim y Colling (2006), Aldé, Mendes y Figueiredo (2006), entre otros.

Para este estudio, hemos definido analizar los editoriales de dos periódicos, O Globo y O Estado de S. Paulo, durante dos períodos históricos distintos ${ }^{3}$. La selección de los periódicos O Globo y O ESP fue llevada a cabo considerando cuatro criterios. El primero es que los mismos tuvieron, más allá de sus modificaciones, presencia en los dos períodos que abarca nuestro análisis. El segundo es que ambos medios de prensa continuaron perteneciendo a las mismas familias, los Marinho para O Globo y los Mesquita para O ESP, más allá de las variaciones producidas en el mercado de prensa y en los modelos periodísticos. Esta permanencia en el tiempo, a la vez que su pertenencia a los mismos dueños, constituye una continuidad que permite estudiar a los mismos en dos períodos históricos distantes.

El tercer criterio fue el de la representación regional, en un país como Brasil que se caracteriza por los regionalismos. En este sentido, se procuró elegir un periódico como O Globo que fuera representativo de Río de Janeiro, considerando la importancia que esta ciudad tenía en los años 1950 como capital política del país (posteriormente sería trasladada a Brasilia en 1960 por el gobierno de Juscelino Kubitschek). Por otra parte, se eligió un periódico como O Estado de S. Paulo, representativo de la visión de las elites y ligado a las familias tradicionales de São Paulo, donde se encuentran los mayores capitales del país y poderosos espacios de influencia político-corporativos.

Finalmente, un cuarto criterio, la tirada, indica que durante los años 1950, O ESP era el periódico paulista más importante (Pilagallo, 2012), 
así como $O$ Globo era el vespertino más vendido 4 en Río de Janeiro, ya que entre 1950 y 1954 vendería todos los años entre 100.000 y 120.000 ejemplares diarios (Goulart, 2007). Con respecto al período correspondiente al 2003-2006, O ESP y O Globo han sido elegidos por encontrarse también entre los periódicos de mayor tirada a nivel nacional. Según el Instituto Verificador de Circulaciones, en el año 2003 Folha de S. Paulo encabezaba las ventas con 314.908 , luego O Globo con 253.410 y luego $O$ ESP con 242.755 .

\section{LA "CRUZADA MORAL" DURANTE EL SEGUNDO GOBIERNO DE GETÚLIO VARGAS}

A pesar de que a comienzos del segundo gobierno de Vargas los periódicos O ESP y O Globo proporcionarían escasa relevancia a la temática de la corrupción, la importancia de esta cuestión iría incrementándose en la agenda pública conforme avanzaba el mandato. Esto sería así especialmente desde la segunda coyuntura de análisis, que tendría inicio con el recambio ministerial de 1953. Desde entonces, aquello que caracterizamos como una "cruzada moral" tendría cada vez mayor espacio en la prensa ${ }^{5}$.

El triunfo de Janio Quadros como prefecto de São Paulo en las elecciones municipales de marzo de 1953, quien era hasta entonces un desconocido profesor (Fausto, 2003; Neto, 2014), sería indicador de un

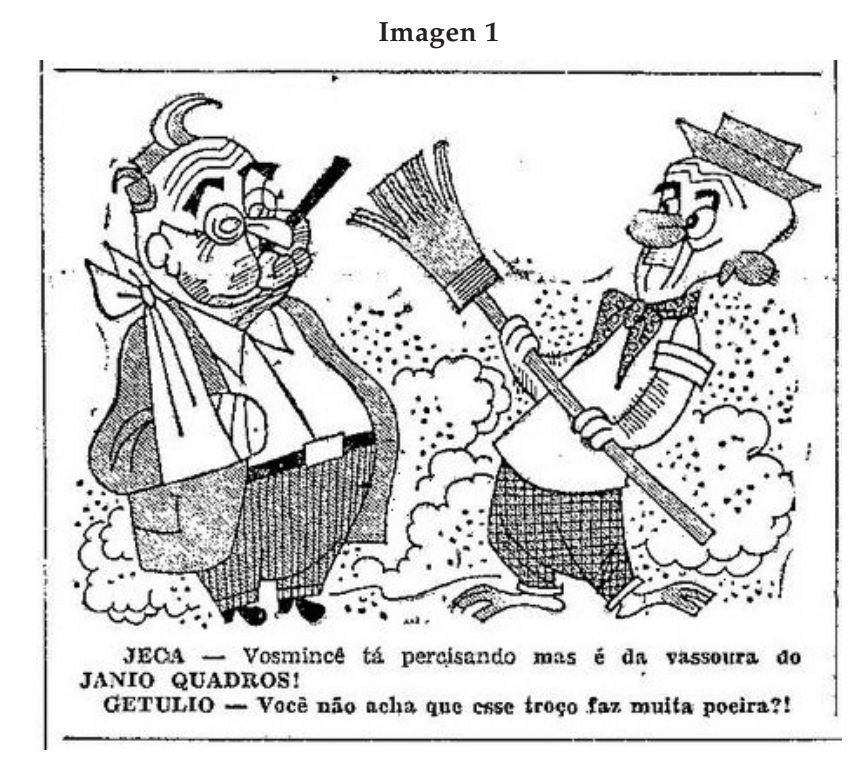

DADOS - Revista de Ciências Sociais, Rio de Janeiro, vol. 60, nº 2, 2017 


\section{Ariel Goldstein}

cambio en el clima político. El mismo se caracterizaría a partir de entonces por las demandas de sanción hacia aquellos políticos acusados de corrupción por parte del electorado paulista. Si bien O ESP había apoyado en las elecciones municipales de 1953 al adversario de Quadros, Francisco Cardoso (Fontes, 2013), posteriormente defendería al primero, definiendo su triunfo como expresión de la lucha contra la inmoralidad que asolaría al país ${ }^{6}$.

A su vez, en este período se desarrollaría el escándalo Última Hora ${ }^{7}$, que afectaría críticamente al gobierno y se situaría en este marco de denuncias contra la corrupción de los políticos. Ya en su edición del 26/5/1953, con el título "A propósito del préstamo del Banco de Brasil a empresas periodísticas" (p. 3), O ESP colocaría en agenda el tema de las acusaciones que habían estallado en Tribuna da Imprensa sobre el caso Última Hora.

Desde mayo de 1953, O ESP insinuaba la corrupción del gobierno, los supuestos negociados en los cuales estaría involucrado, así como su "totalitarismo", dado que la palabra de éste entraría en conflicto con la verdad $^{8}$. Por su parte, en este contexto, en una caricatura en su portada, O Globo (29/5/1953) haría referencia a la posición del gobierno frente a las acusaciones:

En este marco de aparición de las acusaciones por corrupción, especialmente del caso Última Hora, esta caricatura de Théo suponía la resistencia de Getúlio Vargas al desarrollo de las investigaciones que implicaban al gobierno, al exigirle el tradicional personaje Jeca: “iLo que usted está precisando es de la escoba de Janio Quadros!", a lo que Getúlio respondería: ¿No cree que esa escoba genera mucho polvo?”.

El matutino paulista, por su parte, proponía una cruzada del pueblo contra la inmoralidad de los políticos, tanto a nivel estadual como federal ${ }^{9}$, exigiendo apartar a los corruptos y demagogos de la vida pública, así como fiscalizar la corrupción:

(...) el pueblo está cansado de inmoralidades y ya se decidió a castigar a los principales responsables de su ampliación en la administración y la política.

Aprovechémonos de esta reacción instintiva del pueblo para restablecer en la administración y la política el dominio de la seriedad y cerrar la puerta de los cargos públicos de una vez para siempre a los demagogos que abrieron un paréntesis en la línea de honestidad y decencia 
características de la vida política brasileña. No podemos dejar pasar sin una severa condena los deslices políticos y administrativos que salen a la luz. Fiscalicemos con el máximo rigor todo lo que los gobernantes y los políticos hicieran para que, abusando de la indulgencia general de la Nación, no persistan en caminar hacia el pantano para donde los ha llevado el ejemplo de los que, en la Unión y en los Estados, dieron muestras continuas de máximo desprecio por la opinión pública y nunca consideraron infranqueables las barreras que la moral levanta a quienes pretenden hacer de las cosas públicas negocios particulares y de los recursos públicos, recursos personales ${ }^{10}$.

En este marco, una de las exigencias del matutino de São Paulo sería la de "castigar" a través de las elecciones a los acusados de corrupción, impidiendo que continúen participando en la vida política. La cuestión de la "demagogia", resaltada como un atributo negativo, aparecía vinculada con la ausencia de moralidad. Por un lado, el periódico se situaba como representante del sentimiento del pueblo, dotando de significación universal sus intenciones particulares (Ansart, 1983). Por el otro, culpaba a los políticos actuales por haber desviado a Brasil de una historia de honestidad, donde la emergencia de la corrupción parecía remitir exclusivamente a aquel contexto, donde se habría abierto "un paréntesis en la línea de honestidad de la vida política brasileña". Así, se pretendía des-historizar sobre las causas de la corrupción en el país, explicando su emergencia únicamente a partir de aquél contexto, y focalizando para su explicación exclusivamente en factores como la honestidad y la decencia de los políticos. Se pretendía excluir así otras interpretaciones que pudieran conducir a una indagación sobre las causas estructurales de la corrupción en la sociedad brasileña, que pudieran remitir por ejemplo a las apropiaciones históricas de las clases dominantes. De este modo, se proporcionaban encuadres que tenían como pretensión explotar la moralidad en beneficio de determinados intereses políticos.

En este marco, el periódico emprendía contra lo que identificaba como la "corrupción de los políticos", exigiendo aprobar un proyecto para excluir de los cargos electivos a aquellos candidatos que estuvieran involucrados en casos de corrupción ${ }^{11}$. O ESP se refería, en este sentido, a la necesidad de unión para enfrentar a los "corruptos" e "inmorales" en elecciones intermedias de $1954^{12}$.

De este modo, O ESP contribuía a la construcción de un clima donde prevalecía la idea de una "disolución moral", una ausencia de honesti-

DADOS - Revista de Ciências Sociais, Rio de Janeiro, vol. 60, n² 2, 2017 
dad que hundiría y amenazaría los valores de la nación, de la cual sería culpable el gobierno, aunque las acusaciones abarcaban a la clase política en su conjunto, de modo similar al discurso utilizado por Janio Quadros.

Por su parte, O Globo daría gran relevancia al caso Última Hora. En su tapa decía: “En torno a los financiamientos a la empresa Érica y a ‘Última Hora'” (2/6/1953). El copete decía: “Los graves hechos articulados en la tribuna de la Cámara contra los préstamos concedidos por el Banco de Brasil y las explicaciones del director de la Cartera de Crédito Agrícola e Industrial". En la nota abajo, el periódico señalaba su postura frente a los acontecimientos:

Procediendo así, se mantiene O GLOBO una vez más fiel a su línea de imparcialidad, y por eso registra lo más grave que se articuló contra la transacción en la cual fueron parte las empresas citadas y el Banco de Brasil, mientras abre espacio para una explicación por persona autorizada, de los motivos que hayan justificado tal vez el procedimiento de nuestra principal entidad de crédito.

De este modo, O Globo revelaba la pretensión de construir una postura de "imparcialidad" ante el escándalo de Última Hora, que produciría una politización significativa en el campo periodístico. El periódico construía su posición de enunciación desde una pretendida neutralidad y el fomento de la crítica y el debate. Con esta posición pretendía diferenciarse en un campo periodístico polarizado, donde sus mayores expresiones en este sentido en la capital carioca serían Tribuna da Imprensa y Última Hora. En este marco, el vespertino destacaba en un editorial titulado "La intervención del gobierno en la vida de la prensa":

Estamos en contra de la intervención del gobierno en ese campo por entender que la acción oficial tiene otros sectores propios, donde su presencia es más necesaria y provechosa. Además, entendemos que la función principal de la prensa de informar imparcialmente y de criticar constructivamente no se corresponde con la propiedad de órganos informativos por parte del Estado. (...) Esa es la simple lección que nuestros dirigentes insisten en desconocer, aunque los hechos, en Brasil y en el extranjero, muestren cada día que nada puede sustituir a la prensa libre, sin vínculos oficiales, en su noble función pública.

Este discurso manifestaba el malestar de $O$ Globo por la existencia de Última Hora. El editorial se pronunciaba contra la intervención guberna- 
mental en el mercado de medios, exigiendo preservar la "autonomía". Sin embargo, con esta alegación en defensa de la "prensa libre", el vespertino también manifestaba su desacuerdo por la existencia de un nuevo competidor en el mercado de Rio de Janeiro. De este modo, la instrumentación del discurso del patrón norteamericano de la objetividad le permitía a O Globo legitimarse frente a estos acontecimientos e invalidar a Última Hora. El periódico pretendía crear la ilusión en sus receptores de que no tomaba una postura definitiva. Al mismo tiempo, prácticamente todos los días, O Globo anunciaba en su tapa el programa del periodista opositor Carlos Lacerda en la Radio Globo. El vespertino, especialmente durante 1953, daría relevancia a la figura de Carlos Lacerda, promocionando sus programas radiales y sus apariciones públicas. Esto nos permite cuestionar lo destacado por Abreu y Lattman Weltman (1994) sobre la moderación que habría tenido el periódico dentro de los medios de prensa de la época. Esto podría ser adecuado para los días de la crisis de agosto de 1954 que abarcan los autores, pero no es así cuando ampliamos el análisis a la coyuntura de 1953. En ésta última, el vespertino aparecía como un periódico más equilibrado que O ESP, pero otorgaba un espacio relevante en sus tapas a Carlos Lacerda ${ }^{13}$ :

De este modo, O Globo reconocía al líder udenista como el más famoso "cruzado contra la corrupción y el comunismo", en tanto el anticomunismo que era característico del vespertino encontraría en su figura una expresión afín. A su vez, el crecimiento en la popularidad de Lacerda estaría vinculado con la relevancia que iría adquiriendo la temática de la corrupción en la agenda pública.

A través de sus periodistas, O ESP también promovía una interpretación sobre las transacciones de Última Hora con el Banco de Brasil ${ }^{14}$. El matutino exigía mayor perseverancia a la comisión de investigación (CPI) con respecto a las acusaciones que existían sobre Última Hora, considerándolo un caso "doblemente inmoral". Desde el surgimiento del escándalo, O ESP procuraría vincularlo con el presidente, exigiendo un mayor endurecimiento contra la corrupción de los políticos y re-

Imagen 2

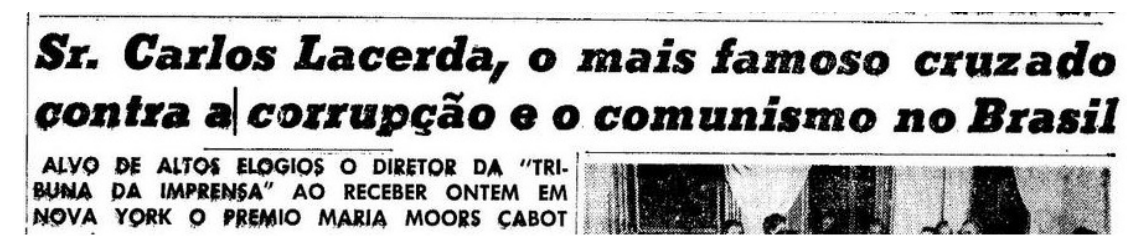

DADOS - Revista de Ciências Sociais, Rio de Janeiro, vol. 60, nº 2, 2017 


\section{Ariel Goldstein}

probando que no hubiera culpables por el préstamo del Banco de Bra$\mathrm{sil}^{15}$. Señalaba que sólo con la movilización y la exigencia ciudadana se podría terminar con esto: “La opinión pública está verificando que sin una reacción violenta de su parte las cosas no cambiarán y Brasil continuará siendo, eternamente, el paraíso de las infamias oficiales"16.

El desarrollo de las acusaciones contra el propietario de Última Hora por parte de los distintos medios de prensa mostraba el ensañamiento existente contra Samuel Wainer. La "cruzada moral" estimulada por la prensa resultaría un componente central en el desgaste que experimentaría el gobierno, especialmente entre las clases altas y medias de San Pablo y Rio de Janeiro. Una gran cantidad de periódicos intentaban encuadrar las demandas de moralización de la política exclusivamente hacia el caso Última Hora y, de forma más o menos directa, hacia el gobierno de Vargas.

En la tapa de O Globo (17/7/1953) figuraba un manifiesto que llevaba la firma de sus dueños Roberto Marinho y Herbert Moses, entre otros propietarios de periódicos, con el título "Defensa de la honra y la independencia de la prensa brasileña". El mismo llamaba a

Tomar una posición en defensa del honor y la independencia de la prensa brasileña, amenazadas por la agresión de los interesados en destruir las instituciones democráticas de Brasil. Así los principales órganos de la prensa brasileña previenen y advierten a la opinión pública contra las simulaciones y los manejos de los que buscan propagar la reprobación del pueblo hacia las empresas periodísticas que están siguiendo atentamente los trabajos de la Comisión Parlamentaria tendientes a caracterizar la creación de periódicos privilegiados para la lucha contra la prensa libre.

Vemos entonces cómo existía en los distintos medios de prensa, especialmente de Rio de Janeiro, un extendido malestar que llevaría a un consenso planteando una "culpabilidad anticipada" en el caso Última Hora. El descontento provenía de la intervención del gobierno para la creación de un periódico a través de un crédito ilegal, lo que era considerado un atentado contra la "prensa libre" y llevaría a la "destrucción de las instituciones democráticas". Esto también se reflejaría en las tapas del vespertino, conforme irían avanzando las acusaciones en la justicia.

A diferencia de la interpretación promovida por O Globo, el columnista Rafael Correia de Oliveira, así como la línea editorial de O ESP, procu- 
raban ver a Wainer como un engranaje del "sistema corrupto" del cual Getúlio sería el máximo responsable:

Si la mera destrucción de Wainer restituyera la decencia en la vida pública nacional, casi no tendríamos problemas que resolver. Pero Wainer es el producto de una situación que él no creó, pertenece a un sistema de aventuras que se extienden hasta los puntos más altos de la administración -y su sacrificio único no resolvería nada en favor de la moralidad pública. (...) No alcanza con destruir a Wainer. Impera destruir el sistema del que él forma parte... ${ }^{17}$.

De este modo, se iría construyendo una naturalización progresiva sobre la idea de Wainer como "aventurero", así como sobre la culpabilidad y corrupción de la familia Vargas, creadora de un "sistema" de negocios público-privados ${ }^{18}$. En este sentido, se vuelve evidente cómo mientras O Globo parecía responsabilizar a Wainer por su competencia con Última Hora en Rio de Janeiro, O ESP utilizaba este escándalo para culpabilizar a Vargas, destacándolo como el principal responsable del mismo. Desde la visión del matutino paulista, Wainer sería expresión de un "sistema" dirigido por Getúlio que se extendería hasta los niveles más altos del poder para asegurar la "corrupción moral" del país ${ }^{19}$. Este tipo de encuadres reiterados tenían la pretensión de involucrar a Vargas y su familia en el escándalo de Última Hora.

La posición de O ESP frente a estos acontecimientos se caracterizaba por un idealismo moralista. Se proclamaban criterios propios para "condenar" y "absolver" acusados, como si el periódico detentara el monopolio de la moralidad, el cual le proporcionaría la capacidad para juzgar, culpar y absolver acusados frente a la opinión pública. En esto, no podía ser ajeno el hecho de que el matutino se considerara el portavoz de las "elites ilustradas" del país.

Uno de los recursos en la argumentación de O ESP para destacar la corrupción del gobierno, consistía en señalar la apropiación de lo público por parte de la familia Vargas, que habría transformado los "cofres del Banco de Brasil" en "anexos de su hacienda personal" ${ }^{20}$. Para el periódico, sería la demostración "de la supervivencia, en pleno régimen democrático, de una estructura administrativa de cuño fascista"21. El matutino se manifestaba justificando en este marco la campaña y los argumentos esgrimidos por el periodista Carlos Lacerda.

En el caso Última Hora, los medios de prensa más importantes iban operando en la construcción de segundas cadenas significantes. La deno-

DADOS - Revista de Ciências Sociais, Rio de Janeiro, vol. 60, n’ 2, 2017 


\section{Ariel Goldstein}

minación de Wainer como el "aventurero", en sus relaciones con el poder involucrando a Vargas, no dejaba de ser relevante en tanto construcción que tomaba por evidente construcciones discursivas previas sobre la corrupción gubernamental (Barthes, 2004). De este modo, se iban solidificando estas cadenas de naturalizaciones, asumiendo, además, como inevitable la caída del gobierno de Getúlio por su "corrupción moral".

Como hemos mencionado, la densidad dada al tema y la crítica desplegada por O Globo en el caso Última Hora sería mayor que en O ESP, por ser un affaire que impactaba especialmente en la capital del país y en su prensa, así como por constituir el periódico dirigido por Wainer una competencia directa del vespertino carioca. Este último sería mucho más crítico con Wainer, encuadrando allí el foco principal de la culpabilidad.

Por su parte, O ESP encuadraba el tema de la corrupción gubernamental como parte de su llamado a la ciudadanía a participar de la "guerra contra la infamia", destacando que cada indicio que aparecía permitiría un mayor conocimiento del sistema corrupto montado por los $\operatorname{Vargas}^{22}$. A través de estos discursos, se iría produciendo una naturalización progresiva, una sedimentación del mito (Barthes, 2004) respecto de las consecuencias catastróficas para la nación que implicarían esta onda de inmoralidad y la corrupción existente. Además, se impulsaba una amenaza sobre el ajusticiamiento popular contra la corrupción que podría sobrevenir en caso de que el presidente no se ocupase de combatirla. De este modo, el periódico vinculaba las denuncias de "corrupción" gubernamental con las denuncias de "subversión" del país. Encarnando una pretensión de universalidad, el matutino señalaba que existiría una nación oprimida por los escándalos de corrupción, que no podría "respirar tranquila" hasta que éstos no se resuelvan. Se definía así la cruzada contra la corrupción de los políticos para el renacimiento nacional:

El día en que la corrupción sea combatida sin tregua y los corruptores estén seguros de que no quedarán impunes, cambiará el escenario político y administrativo de Brasil y de San Pablo y la esperanza de mejores días renacerá en el corazón de todos los que viven angustiados con la depresión moral de esta época y con la incurable incompetencia de nuestros gobernantes ${ }^{23}$.

De este modo, O ESP cifraba los motivos del drama nacional en la ausencia de moralidad y civismo de los políticos, indicando que una vez 
que aparecieran dirigentes que respetaran estas dos condiciones, los problemas del país estarían solucionados. La unión contra la corrupción sería la clave para un renacimiento nacional, ya que todos los males del país remitirían a esta cuestión. Esta moralización de la actividad pública suponía una búsqueda de abstracción de la lucha política, una política de la nobleza moral antes que de lucha por el poder, que era coincidente con la visión de los bachareis udenistas.

A su vez, esta interpretación recurrente en ambos periódicos contenía un componente mesiánico, dado que cifraba todos los "males" del país en la ausencia de honestidad. De este modo, proponía de forma simplista que los problemas del mismo estarían solucionados cuando acabara la "corrupción" de los políticos. Así, se manifestaba en la construcción de esta simple fórmula que buscaba forjar el sentido común, la utilización de la moral como estrategia orientada en función de las aspiraciones de estos medios de prensa de incidir como actores políticos y económico-comerciales.

Así, se mostraba la vocación del matutino por situar la cuestión moral en un primer plano entre las problemáticas de la nación, frente a otras temáticas que se buscaba desde el gobierno colocar en el centro del debate público, como la desigualdad social. Es decir, confrontaban aquí dos agendas opuestas, la agenda moralista promovida por O ESP y la UDN, que subordinaba la política a la distinción entre "honestos" y "corruptos", y la agenda gubernamental, que pretendía situar a la cuestión de la desigualdad como un eje central del accionar del Ejecutivo. Se manifestaba así un conflicto entre cosmovisiones que pretendían excluirse mutuamente. En este sentido, O ESP señalaba que tanto el Congreso como la prensa eran una barrera para la defensa de la moralidad contra la corrupción y los "aventureros", encarnados en el gobierno del "ex dictador" Vargas.

Hacia fines de 1953, también O Globo iría adscribiendo a esta "cruzada moral" a la cual adherían varios medios de prensa. El vespertino se refería al escándalo Última Hora como el más importante que habría existido, a la vez que designaba a Wainer y su grupo como la "camorra aventurera" ${ }^{24}$, resaltando la nacionalidad extranjera del periodista y creando en la narración efectos sombríos sobre el accionar de este "grupo". También aparecía la referencia a la competencia desleal que significaría el financiamiento gubernamental a Última Hora con respecto a otros medios de prensa. Al mismo tiempo, sostenía que no se podría 
dudar de la familia de Vargas y su honestidad, encuadrando la cuestión de un modo distinto a $O E S P$, que definía al presidente como el principal responsable de este escándalo. El vespertino elegía cargar toda la responsabilidad en Wainer, a la vez que destacaba la indignación generalizada que existiría entre los ciudadanos sobre este escándalo. De este modo, O Globo adscribía a la idea de que la corrupción de un grupo de "aventureros" habría llevado al país a la degradación moral. El vespertino asumía también definiciones similares a O ESP que consistían en señalar la necesidad de liquidar a los corruptos y la corrupción a través de una campaña moralista:

Comienza a soplar en todo el país un viento de indignación capaz de barrer para siempre de nuestra vida pública los métodos espurios que sólo sirven para degradarla. Las voces que en el Congreso se levantan indignadas son un buen reflejo de los sentimientos de protesta que inflaman a los brasileños de todos los cuadrantes de la Patria. Ha llegado el momento de decir basta a los corruptos y a los corruptores. Llegó un momento de levantar un dique a la desmoralización y la venalidad. Al Congreso, más que a cualquier otro poder, le corresponde en esta hora, la misión histórica de luchar por la restauración de la moral en nuestra vida pública ${ }^{25}$.

En estos editoriales, O Globo comenzaría a compartir con O ESP esta cruzada "por la restauración de la moral" en la vida pública. El periódico carioca se caracterizaba, más allá de su identidad conservadora, por la flexibilidad de sus posiciones políticas, vinculada con una estrategia comercial sensible a los cambios en los humores sociales. De este modo, el vespertino adscribiría a la "cruzada moral", reduciendo las diferencias que en torno a este tema presentaba inicialmente con $O$ $E S P$, señalando las consecuencias penosas a nivel nacional que podrían sobrevenir si no se daba prioridad a las exigencias de una restauración moral.

Las tapas de $O$ Globo en este período demostraban que el vespertino apostaba por el sensacionalismo para encuadrar los "escándalos políticos" y proyectarse a nivel comercial. La cobertura de los escándalos era realizada con la pretensión de obtener un rédito tanto comercial como político, a diferencia del matutino paulista, cuyo propósito parecía orientado a afectar directamente al gobierno de Vargas. El discurso moralista colonizaría el discurso político, excluyendo visiones alternativas sobre el litigio que es propio de la lucha política (Ranciere, 1996), o la controversia sobre las desigualdades, para subordinar la política a 
la distinción entre "honestos" y "corruptos". A tono con este clima, $O$ Globo titulaba en una de sus tapas que "es preciso detener la avalancha de corrupción que infecta la vida política y administrativa" $(17 / 2 / 1954)$.

Con la presentación de un pedido de impeachment al presidente por parte de la oposición en mayo de 1954 volverían a surgir dos posiciones distintas por parte de estos medios de prensa. Sobre el tema, O ESP manifestaba que, dada la cantidad de delitos que habría acumulado el presidente, ésta sería la oportunidad para desplazarlo del gobierno, dado que "pocas veces un jefe de gobierno acumuló contra sí mismo delitos tan numerosos y tan evidentes ${ }^{\prime 26}$. El periódico pretendía que se avanzara en la tentativa de impeachment a Vargas en el Congreso, para que se produjera una crisis en la legitimidad del gobierno y ésta quedara como "antecedente de su corrupción". Así, el matutino recomendaba centrarse en los escándalos de corrupción para "esclarecer" lo nefasto que habría sido la presidencia de Vargas. De este modo, señalaba que: "un presidente pésimo, solo puede ser nocivo al país, mientras permanezca en el gobierno. Dejar que pase la oportunidad de desplazarlo del cargo, cuando esa oportunidad se ofrece, es prestar a la Nación el peor de los servicios"27. O ESP amenazaba con equiparar culpables y cómplices si los diputados no votaban por el impeachment a Vargas, exhortando a no despreciar la oportunidad que se presentaba para desplazar al presidente del poder $^{28}$.

Por el contrario, O Globo (2/6/1954) estamparía en su tapa una volanta que decía "Se arma la batalla del impeachment". El título debajo decía: "No tiene ilusiones el propio líder de la oposición". En el copete: "Y el Sr. Gustavo Capanema asegura que la denuncia contra el presidente de la República será juzgada improcedente". Analizando las distintas tapas de esta coyuntura, resulta visible que el vespertino repudiaba el pedido de impeachment hacia Vargas, señalando en sus titulares que ni siquiera el líder de la oposición estaría seguro de la eficacia de esta solicitud, así como citando a líderes del gobierno que se oponían a este proceso. Así, era evidente el rechazo de $O$ Globo hacia la tentativa de destitución promovida por la oposición, lo cual se manifestaba en el vespertino dando espacio a declaraciones que se pronunciaban contra el procedimiento o en titulares en favor de la estabilidad gubernamental.

Ya en junio de 1954, el agrietamiento de la situación política llevaría al matutino a exigir una extirpación de Vargas y su familia como única salvación de Brasil: 
Ariel Goldstein

Mientras esos individuos representen alguna cosa en la política del Brasil, esta no será purificada adecuadamente y la descomposición moral continuará sintiéndose en todos los lugares y en todas sus formas. El mayor enemigo de Brasil y su democracia no es, como se supone, el Partido Comunista. Sus mayores enemigos son el jefe de gobierno y su familia. De ellos es que han venido la serie de males que sufrimos y ellos constituyen un peligro permanente para la tranquilidad y la estabilidad de las instituciones ${ }^{29}$.

De este modo, se manifestaba una radicalización del lenguaje político que exigía extirpar a los Vargas para permitir la restauración moral del país, indicando a los mismos como los mayores enemigos de Brasil y de la democracia. Resultaba este un pedido que iría in crescendo con el pasar de los días. O Globo, desde su propia tradición, también iría radicalizando sus alocuciones y participando del mismo clima:

NADIE se atrevería a negar la terrible crisis de descomposición política y moral que asola la actualidad brasileña. Es una atmósfera de fin de régimen, un ambiente de incredulidad en los hombres y -lo que es peor- en las propias instituciones que domina todo y a todos. No es para menos desde que la corrupción del Gobierno y los métodos de los agentes del Poder Público llegaron a tal punto que los crecientes y repetidos escándalos ya casi no logran conmover o impresionar a la opinión pública.

(...) Estamos a menos de noventa días de las elecciones para la renovación de la Cámara de Diputados, de dos tercios del Senado de la República y de los gobiernos de once Estados, entre ellos algunos de los mayores y más importantes. Por una influencia maléfica del Gobierno Federal, por maquinaciones ostensibles de los principales líderes del oficialismo trabalhista, se confunden casi por todas partes los valores electorales y partidarios.

(...) Pero que nadie se ilusione. Todas las épocas de corrupción tuvieron siempre su rescate. La demagogia comuno-trabalhista está gastando las reservas finales de su nefasto tesoro. El tres de octubre no está lejos y también en la política los molinos de Dios se desintegran lentamente, pero se desintegran ${ }^{30}$.

El vespertino se refería críticamente al gobierno, como si éste tuviera la pretensión de distorsionar en su favor las elecciones intermedias. A la vez, señalaba que le quedaría poco tiempo a la "demagogia comuno-trabalhista", habiéndose así acabado su ciclo político, dado que el "3 de octubre no está lejos". Esto es significativo pues hasta el momento no se había dirigido el periódico en estos términos hacia el gobierno. 
Sin embargo, paulatinamente, se iría tornando fuertemente crítico de la "corrupción gubernamental", adscribiendo al clima de la "cruzada moral" y denunciando la descomposición del país. A su vez, O Globo buscaba una salida electoral a la crisis, diferenciándose así del matutino paulista.

Así, hemos analizado cómo iría ganando intensidad y desarrollándose esta "cruzada moral". Frente a la emergencia de los escándalos de corrupción habría diferencias en el tratamiento por parte de los periódicos, pero a medida que aumentaba el sentimiento de disconformidad social frente al gobierno, irían acercándose en las posiciones condenatorias. Como hemos visto, O Globo, que ha sido reseñado por Abreu y Lattman Weltman (1994) como más moderado en la coyuntura de agosto de 1954, demostraría durante 1953 una gran afinidad con la campaña moralista impulsada por Carlos Lacerda y sus proclamas intransigentes contra la corrupción gubernamental, anunciando sus alocuciones en Radio Globo y resaltando con énfasis sus declaraciones.

En el caso del matutino paulista, habría más constancias que variaciones, pero se verificaría una radicalización del lenguaje condenatorio en forma progresiva, a tono con el crecimiento del malestar social. Especialmente en $O E S P$, se verificaría la utilización instrumental de las acusaciones de corrupción para hacer mella en el gobierno. En $O$ Globo, si bien esto se manifestaría, coexistiría con una explotación sensacionalista de los escándalos. Sin embargo, mientras O ESP encuadraría el caso Última Hora como la expresión de un sistema corrupto, dirigiendo sus críticas y utilizando este escándalo para erosionar la imagen de Vargas, O Globo centraría sus denuncias en Wainer y su grupo, la "camorra aventurera". Esto último se explica por la competencia directa que el vespertino tenía con Última Hora en el mercado carioca.

Esta "cruzada moral", de la cual sería expresión el triunfo de Quadros a la intendencia paulista, si bien encontraba en el caso Última Hora uno de sus íconos fundamentales, excedía esta cuestión, al direccionarse las acusaciones por una purificación de las costumbres morales a toda la clase política. La adhesión con la que contaría esta colonización de la política por el discurso moralista sería también expresión de los temores en los sectores medios ante una sociedad en transformación. La subordinación de la política a la distinción entre "honestos" y "corruptos" brindaba seguridad, en tanto excluía visiones alternativas que pudieran ser percibidas como riesgosas para la reproducción del

DADOS - Revista de Ciências Sociais, Rio de Janeiro, vol. 60, n’ 2, 2017 


\section{Ariel Goldstein}

orden social. De este modo, la moralización de la política contribuiría en este contexto para la naturalización del orden social, garantizando la exclusión de otras problemáticas de la agenda pública.

\section{LA CRUZADA MORAL CONTRA LULA Y EL PT}

Durante el primer gobierno de Lula da Silva (2003-2006), las críticas por corrupción por parte de ambos medios de prensa se centrarían especialmente en el Partido de los Trabajadores (PT) y en la figura del presidente $^{31}$. Las acusaciones más fuertes por parte de estos medios emergerían a partir del estallido del escándalo del "mensalão" en mayo de $2005^{32}$.

Sin embargo, ya desde mediados de 2003 comenzarían a aparecer en $O$ Globo y O ESP encuadres referidos al denominado aparelhamento del Estado, donde se criticaba la supuesta distribución, orientada de forma exclusiva por criterios político-partidarios, de los cargos y nombramientos en los organismos públicos estatales. O Globo, que titularía, "El gobierno privilegia un criterio político para llenar los cargos" (31/8/2003), acusaría al PT de haber ocupado el Estado con criterios ideológicos y "corporativistas", propios del sindicalismo ${ }^{33}$, que perjudicarían el funcionamiento de la "máquina pública". En este sentido, señalaba que

Es comprensible que los partidos victoriosos en las urnas ocupen espacios en las administraciones. Los problemas surgen cuando la lapicera que nombra no tiene en cuenta el claro principio de la necesidad de que el nombrado tenga competencia técnica para el cargo - sin olvidar la calificación ética.

(...) La llegada al poder de grupos que jamás participaron de él causaría un choque y acomodaciones en el terreno. Pero no era previsible que exactamente el partido cuyo discurso es el de la modernización y la moralidad sería el agente de la vuelta de la práctica arcaica del amiguismo, ejercida también cuando los cargos son ocupados en función de trajes ideológicos ${ }^{34}$.

De este modo, con el propósito de invalidar el accionar del partido, el matutino carioca sostenía que el PT estaría restaurando el "fisiologismo" al ocupar el Estado con nombramientos guiados por criterios políticos. Por su parte, la periodista Lucía Hippolito sería crítica de lo que consideraba como el "modelo compañero-militante", el cual estaría "poblando la máquina pública de sindicalistas y participantes de mo- 
vimientos sociales, que parecen ignorar los requisitos mínimos para gobernar un Estado ya bastante complejo y sofisticado como el Estado brasileño" ${ }^{\prime 35}$. Esta cuestión manifestaba cierto prejuicio de clase, al señalarse de forma implícita que el Estado sólo podría ser administrado por funcionarios que tuvieran determinadas "competencias", desvalorizando los nombramientos de sindicalistas e integrantes de los movimientos sociales por parte del PT.

Por su parte, O ESP realizaría una crítica de lo que percibía como la ocupación del Estado por parte de los militantes petistas, reproduciendo en esta cuestión también el par que diferenciaba entre pragmatismo/técnico e ideología/criterios políticos:

(...) (estos espacios) estaban ocupados por técnicos calificados, indispensables para el funcionamiento de la máquina estatal, cuando el PT llegó al gobierno. Su sustitución en masa por militantes partidarios, ajenos a la rutina y los procedimientos burocráticos de la administración, sólo podía resultar en la parálisis de la máquina estatal, en una enorme confusión en las distribuciones y en la lentitud del proceso de toma de decisiones. No se pensó, en ese proceso, en el usuario del servicio público ${ }^{36}$.

Así, el matutino condenaba esta situación como la mayor ocupación del Estado orientada por criterios partidarios desde la redemocratización del país. Durante estos días, O ESP construiría una sección de noticias dedicada específicamente a las denuncias por aparelhamento del Estado, que llevaba el título de "Gobierno Loteado", prolongándose durante varios días. El periódico colocaba el titular: "La máquina pública está atascada; 70\% de los nombramientos son políticos" (31/8/2003).

Con este tipo de construcciones, ambos periódicos procuraban construir una estigmatización sobre la militancia del PT y sus prácticas políticas, generando la imagen de un Estado que previo a la llegada de este gobierno habría sido puramente "técnico" e "incontaminado" de militantes, proceso que sería revertido con el PT y el gobierno de Lula.

Durante el segundo período, correspondiente al escándalo del "mensalão", la agenda pública exhibiría un centramiento en torno a la temática de la corrupción partidaria y gubernamental. El trabajo elaborado por Miguel y Coutinho (2007) sobre los encuadres asumidos por los editoriales en O Globo, Folha de S. Paulo y O ESP durante el período que duró el escándalo, resulta relevante para nuestra comprensión. De este modo podemos apreciar, en comparación con otros medios de prensa,

DADOS - Revista de Ciências Sociais, Rio de Janeiro, vol. 60, n’ 2, 2017 


\section{Ariel Goldstein}

la importancia que tenían las acusaciones de corrupción en O ESP centradas en Lula y el PT como forma de explicación de la crisis política. Según nuestro análisis, durante este período habría en O ESP una predominancia de editoriales (39) referidos a un encuadre que denunciaba el paso del PT de "denunciante de la corrupción a líder en corrupción: de proyecto político a proyecto de poder". Este encuadre supondría la acusación de que se habría producido una inversión de valores o una perversión ética en el PT. Para el periódico, el partido habría pasado de protagonista en la lucha contra la corrupción a realizar el gobierno más corrupto de la historia del país, con el propósito de perpetuarse en el poder.

A su vez, el resultado de nuestro análisis confirma los señalamientos de Miguel y Coutinho (2007) de que O Globo sería el periódico que más acusaría como causa de la crisis al aparelhamento del Estado que habría realizado el PT, exigiendo una reforma política y una modernización estatal para reducir los cargos políticos. Es decir, el encuadre del aparethamento como causa de la crisis política estaba más representado en $O$ Globo que en O ESP. Por el contrario, el matutino paulista centraría su ataque en la incapacidad de Lula y en la corrupción del PT, definiendo a éstos como los responsables de la crisis. En este sentido, Miguel y Coutinho indican que en $O E S P$ existió un anti-petismo y un anti-lulismo más acentuados que en otros periódicos. Los analistas sostienen también que en comparación con los periódicos paulistas, O Globo resultó más moderado frente a esta crisis (Miguel y Coutinho, 2007: 116). Además, el periódico carioca habría presentado más propuestas de soluciones a la crisis que los periódicos paulistas.

El periódico de Rio de Janeiro sostenía que esta crisis definiría el futuro del PT. Así, entendía que el gobierno debía dar respuestas a estos acontecimientos modernizando el Estado y reduciendo los cargos políticos, ya que éste sería el origen de los escándalos de corrupción:

El escándalo proporciona un favor al país exponiendo esta red existente en la máquina pública, por la cual la política se degrada y deviene un negocio sin escrúpulos. Como la fuente de alimentación de las cajas dos y los mensaloes está, obviamente, en estos cargos de administración directa y las empresas estatales, está claro que la manera más eficaz para luchar contra la corrupción es reducir o eliminar los espacios de acción de la corrupción, a través de una reforma que reduzca el tamaño del Estado $^{37}$. 
Así, O Globo promovería el encuadre de que las causas de la crisis estarían en la amplitud estatal y por ello, la solución de la misma residiría en la implementación de una reforma que redujera los cargos políticos y el "tamaño del Estado". El periódico también sostenía que esta crisis sería una oportunidad para introducir una reforma política que tornara más rígida la fidelidad partidaria, impidiendo el troca-troca de los partidos, reduciendo su número y las negociaciones ${ }^{38}$.

Por su parte, a partir de la emergencia del mensalão, O ESP actualizaría la crítica descalificadora hacia el $\mathrm{PT}$, que se mantendría como una constante durante nuestro análisis, y pasaría de estar centrada en torno a la denuncia del partido como "radical e irresponsable" a inicios del gobierno, hacia una nueva descalificación del mismo como "partido corrupto". La emergencia del mensalão le permitiría al periódico redefinir en forma más efectiva su función discursiva descalificadora hacia el partido. De este modo, primaría el encuadre que acusaba al PT de haber cambiado su proyecto ético por un mero "proyecto de poder", habiendo pasado de la lucha contra la corrupción, a realizar el gobierno más corrupto de la historia brasileña:

(...) cada día el Planalto consigue producir actos y palabras más penosos que los del día anterior -capaces de sorprender incluso a todos los que saben de qué materia-prima se hacen muchas veces las decisiones políticas y nunca alimentaron ilusiones sobre lo que sería el 'modo petista' de conservar el poder.

En esa escalada de degradación del pasado de un partido en el que no faltaba lo que criticar -pero en el que había también que respetar el inconformismo con las inequidades sociales brasileñas y una convicción no menos autentica de que la política no está determinada a ser sinónimo de robo-, el PT palaciego mostró a qué vino. Con obstinación y cinismo, se excedió en las prácticas que los petistas no se cansaban de reprobar, sin siquiera tener para invocar una causa noble para justificar las manos sucias.

(...) Reproduciendo con impecable fidelidad las prácticas que otrora prometían remover de la escena política, los compañeros alojados en el Planalto y los que a ellos obedecen en el Legislativo abrieron los cofres e instalaron el látigo ${ }^{39}$.

Comenzaría a esbozarse así en O ESP el encuadre de que el PT, en su afán desmedido de poder, habría invertido su práctica política, transformándose del partido de la ética al partido del "vale-todo" para permanecer en el poder. Esta organización, que había nacido con la con-

DADOS - Revista de Ciências Sociais, Rio de Janeiro, vol. 60, no 2, 2017 


\section{Ariel Goldstein}

signa de la ética en la política, habría pasado de esa posición de denuncia frente a la corrupción a transformarse, según la óptica del periódico, en el partido que habría institucionalizado la corrupción ${ }^{40}$. De este modo, la crisis le brindaría a O ESP la oportunidad de estigmatizar el pasado de izquierda del partido, haciendo al PT responsable exclusivo de estos acontecimientos, ignorando los discursos que vinculaban la emergencia de la crisis con la naturaleza propia del sistema político. Para el periódico, el PT sería el único que podría haber hecho esto en función de su pertenencia de izquierda. De este modo, se instrumentalizaban las causas y los efectos de la crisis para promover una interpretación funcional a la línea ideológica del matutino.

El periódico paulista en sus titulares ${ }^{41}$ y columnas procuraba dar la idea del PT como un partido en descomposición, que habiendo perdido su ética, ahora perdería a sus militantes. O ESP persistiría augurando de forma constante un agravamiento de la crisis política y la aparición de nuevos escándalos. Destacaría que cuanto más declaraban los petistas, menos motivos habría para terminar con las indagaciones $^{42}$.

Por su parte, O Globo compartía este encuadre de la inversión, aunque sin tantos editoriales y columnas de opinión referidos a la cuestión:

La crisis actual marca la derrota de un proyecto de poder autoritario, y que desarrolló una deformación letal para cualquier sociedad: una faceta criminal, con vínculos en el bajo mundo de los negocios, en el cual procuraba abastecerse de dinero oscuro para financiar las campañas electorales y sellar alianzas parlamentarias. Y así perpetuar en el poder a un grupo.

Es posible establecer vínculos entre el rostro ilegal y criminal de la actuación por parte del PT y los avances de carácter autoritario, realizados por el gobierno petista contra la libertad de expresión y los derechos civiles $^{43}$.

De este modo, para este diario la crisis también significaría la demostración del autoritarismo del PT, así como de su carácter corrupto y criminal, invalidando el futuro del partido y su continuidad como proyecto político. A su vez, O ESP manifestaba su pretensión de impugnar el pasado del partido, invalidando su existencia desde el origen:

(...) el PT se dio el derecho de hacer lo que condena en los demás partidos, porque estos lo hacen por mera ambición -y él, para transformar el 
País. En rigor, la lógica de los que pasaron a hacer, en nombre de la Causa y en todos los niveles del gobierno, lo que decían abominar, es idéntica a la de muchos de los cuadros del futuro PT, en el giro de los años 1960 para los 1970. Con el pretexto de combatir la dictadura, ellos "expropiaban" bancos para reunir recursos que les permitieran llevar adelante su proyecto guevarista. Ahora, expropian el Estado. Por lo visto, en el PT o se es extremista y arcaico, o se es moderno y corruptor ${ }^{44}$.

El periódico, en el momento de explicar las causas de lo que percibía como la "corrupción petista", se remontaba a los orígenes del partido para explicar las conductas actuales de sus miembros. De este modo, pretendía invalidar la práctica política del PT en sí misma, utilizando las acusaciones de la coyuntura como forma de desacreditar su existencia partidaria. Así, este diario insinuaba que la opción política petista, por estar "podrida como una manzana", quedaría deslegitimada a partir de entonces.

Como vemos, O ESP construiría una apelación al pasado para potenciar la fuerza con que se condenaba el presente, buscando el origen de la corrupción en una "marca de nacimiento" que condicionaría toda la existencia posterior del PT. En contraposición con la definición petista, que aspiraba a penalizar a ciertos militantes que identificaba como responsables de las acusaciones de corrupción, recurriendo a su historia como legitimación de sus prácticas presentes, el periódico pretendía enjuiciar al partido mismo y su existencia política.

En continuidad con esta operación discursiva, el matutino sostendría que lo que habría realizado el PT a nivel nacional no sería más que la institucionalización de la corrupción que habría desarrollado primero a nivel municipal ${ }^{45}$. El matutino asociaba las acusaciones de corrupción de este contexto con una corrupción intrínseca en el partido, que se remontaría a la administración de las intendencias ${ }^{46}$. Como podemos observar, tendría lugar frente a la crisis la activación de una disputa entre el partido, los medios y sus opositores por la definición legítima del origen petista.

De este modo, conforme se desarrollaba la crisis política, O ESP procuraba acrecentar su definición de este gobierno como el más corrupto de la historia nacional. Sostenía que mientras el PT se dedicaba, cuando estaba en la oposición, a denunciar la corrupción de "los que estaban", estos últimos eran una banda de aprendices frente a lo que el PT habría de realizar en el poder" ${ }^{47}$. Así, el periódico criticaba "la podredumbre

DADOS - Revista de Ciências Sociais, Rio de Janeiro, vol. 60, n² 2, 2017 


\section{Ariel Goldstein}

del partido, carcomido por el oportunismo sin límites y la corrupción" ${ }^{48}$. De este modo, aseveraba que: "si Lula no quiere que su gobierno se termine, debe separar la ética del gobierno de la ética del $\mathrm{PT}^{\prime \prime 4}$.

El periódico sostenía que el partido habría derivado en un grupo totalitario que, en la mezcla de un afán de poder sin límites con una "ética revolucionaria" -que le hacía creer poseer el monopolio de la moral viendo la corrupción sólo en los otros- habría destruido las instituciones, transformándose en un proyecto totalitario de permanencia en el po$\mathrm{der}^{50}$. El periódico paulista condenaba a todos los petistas ya que, desde su visión, el mensalão habría resultado una realización colectiva. La corrupción sería colectiva y generalizada, en función de la aspiración partidaria de apropiarse del Estado para perpetuar un proyecto de poder. En la concepción del periódico sobre el partido, cada aparición era reconocida como representando el exceso: o el ideologismo extremo o los deslices éticos, estableciéndose vínculos entre ambas definiciones. Como hemos visto, el matutino lo señalaría claramente: "Por lo visto, en el PT o se es extremista y arcaico, o se es moderno y corruptor"51.

Una definición relevante de $O E S P$, vinculada con las acusaciones de querer desvirtuar las investigaciones sobre las acusaciones de corrupción, suponía la cuestión de la culpabilidad de Lula frente al "mensalão". De este modo, presumiendo la culpabilidad de Lula, O ESP oscilaba entre señalar que el presidente era o un lunático como pocos, o un fingidor, puesto que no podría ignorar haber tenido informaciones sobre la existencia del mensalão previo a las declaraciones públicas del diputado del PTB Roberto Jefferson: "O el presidente fingió, o su memoria falla" ${ }^{52}$. El periódico insistiría en la culpabilidad de Lula en el mensalão, señalando que habría una "objetiva responsabilidad política del presidente de la República por las violaciones de la ley que lo benefician" ${ }^{\prime 2}$.

Como hemos referido, una de las causas que O ESP identificaría para la crisis política, y en este sentido compartía con $O$ Globo, sería la excesiva ampliación del Estado promovida por el gobierno petista. El periódico señalaba que

(...) cuanto mayor sea el espacio ocupado por el Estado, o el número y el tamaño de las empresas estatales, tanto mayor será el margen de maniobra del fisiologismo político-partidario, para el clientelismo y los desvíos de recursos públicos con finalidades electorales o cualquier otra, 
aumentando, así, aquello que se denomina como crimen de corrupción ${ }^{54}$.

Así, la amplitud del Estado sería la causa de la crisis política, defendiendo el matutino paulista a las privatizaciones como reductoras del volumen de cargos existente. Al percibir la debilidad política del gobierno, O ESP intentaba condicionarlo produciendo una vinculación entre la amplitud del Estado y el aparelhamento, aludiendo a una restricción de las capacidades estatales y del número de cargos públicos como solución para afrontar la crisis política ${ }^{55}$.

La situación comenzaría a cambiar con la elección de Aldo Rebelo (PCdoB), para la presidencia de la Cámara de Diputados, en reemplazo de Severino Cavalcanti (PP). Ambos periódicos a partir de entonces reducirían las críticas dirigidas al PT y las enfocarían más en la clase política en su conjunto, así como en la posibilidad de un "gran acuerdo" que encubriría los hechos de corrupción que se estaban investigando.

En el caso de O Globo, a partir del triunfo de Rebelo como presidente de la Cámara en octubre de 2005, comenzarían a cambiar los encuadres referidos a la crisis del mensalão. El periódico carioca sostenía que todo podría terminar en "pizza", tapado por conveniencias políticas, enunciando la necesidad de que las investigaciones continuaran. Este aspecto se convertiría en un encuadre importante del periódico durante el período:

A pesar de los descubrimientos y las revelaciones hechas sobre el propinoducto del PT -cuya existencia es incuestionable - acciones coordinadas por petistas, discursos que pretenden disimular y cierta clemencia en la conducción de las CPIs ayudan a consolidar la idea del fracaso irreversible en las investigaciones. Y de que habría un acuerdo entre parte de la oposición y del oficialismo, para preservar los mandatos de los cuestionamientos, inaceptable para la opinión pública.

(...) Le corresponde a las CPIs y a las autoridades responsables del gobierno evitar la distorsión de las investigaciones. No se puede ser complaciente con recursos "no declarados", de caja dos, como el propio Ministro de Justicia, Marcio Thomaz Bastos, afirma.

Ni fingir que la dificultad para localizar con exactitud el origen del dinero del mensalão puede encubrir la existencia del propio mensalão $(\ldots)^{56}$.

De este modo, el periódico se pronunciaba contra un "acuerdo" a partir de la elección de Rebelo como presidente de la Cámara de Diputa-

DADOS - Revista de Ciências Sociais, Rio de Janeiro, vol. 60, n² 2, 2017 
dos, el cual podría significar desde esta visión que no se investigara más el mensalão en el Congreso.

O ESP también moderaría su línea editorial hacia noviembre, en conjunción con la asunción de Aldo Rebelo como presidente de la Cámara de Diputados y la pretensión del periódico de reducir las acusaciones de los petistas contra las elites y los grupos de poder. A fines de esta segunda coyuntura, el periódico utilizaría un tono más moderado, cambiando los encuadres que culpabilizaban al PT íntegramente por la crisis política y comenzando a incluir encuadres que abarcaban a todos los políticos como responsables de la crisis. De este modo, ambos periódicos actuarían de un modo similar a partir de la elección de Rebelo como nuevo presidente de la Cámara.

Durante el tercer período de análisis, correspondiente a las elecciones presidenciales de 2006, la cuestión de la corrupción sería uno de los temas dominantes de la campaña. En este sentido, Mundim señala que

Un espectro rondaba la elección presidencial de 2006: el espectro del Mensalão. A comienzos de año la magnitud de sus efectos sobre los electores era una incógnita y una incomodidad para el gobierno que buscaba la reelección, todavía más con una cobertura mediática tan negativa (Mundim, 2010: 119).

En este período, O Globo promovería encuadres que señalaban la necesidad de castigar a los corruptos, pero de un modo que hacía entrar dentro de aquella denominación a la clase política en su conjunto. El periódico carioca plantearía la elección en los términos de una disputa regida por la lucha de la ética contra la corrupción, y especialmente a partir de la aparición de un dossier contra José Serra que habría sido comprado por militantes petistas, difundiría un encuadre relativo al PT como un partido sin moral e integrado por delincuentes.

O ESP, por su parte, situaría al PT como responsable de la corrupción, preservando el encuadre dominante de la perversión ética del partido, que identificaba a éste con el paso de un proyecto político a un proyecto de poder. El matutino paulista insistiría en criticar la "corrupción inherente para permanecer en el poder" del PT. Nuevamente, se recurría a la genealogía que planteaba la falsedad en el origen, señalando la "esencia" de la corrupción petista, instalado primero en las intendencias y luego a nivel nacional para preservar el poder y conseguir la reelección ${ }^{57}$. De este modo, el matutino seguiría insistiendo en el 
origen corrupto de esta trama partidaria que se expresaría en toda su intensidad en el presente ${ }^{58}$. El periódico repetiría así que la corrupción del mensalão sería inherente al proyecto de reelección del PT para asegurar su permanencia en el poder.

O ESP reiteraba la disposición de los petistas a cualquier ruptura ética con el fin de perpetuarse en el poder, así como señalaba a los acusados de corrupción como parte de una "organización criminal", tal como lo había señalado el Procurador General de la República ${ }^{59}$. El periódico sostenía:

Pero la realidad es que a toda hora aumenta el papel de los bandidos del petismo, permitiendo que se trace una línea que avanza desde las sombras para el centro visible del sistema.

(...) La trayectoria del PT, desde su inserción en el movimiento sindical, muestra que es típico de sus dirigentes y asociados recurrir a cualquier medio para destruir a aquellos a quienes marcaron, incluso al riesgo de ser afectados ellos mismos -lo que tiende a suceder cuando no se tiene sentido de los límites éticos, o cuando la transgresión sin frenos, aunque reconocida como tal, es legitimada en nombre de una causa. (...) Por eso llega a ser bizantino discutir si Lula sabe de sus delitos desde antes o mientras son cometidos: él sabe de lo que su gente es capaz, porque de ella no se distingue. Ni en el modus operandi ni en los fines ${ }^{60}$.

No resultaba importante para el periódico definir si Lula sabía de la existencia previa del mensalão: el partido y sus integrantes ya estarían condenados de antemano por su modus operandi, el cual prescindiría de consideraciones éticas. Así, en la exhibición de las acusaciones de corrupción por parte de los principales medios de comunicación, operaba el principio de "presunción de culpa" (Lima, 2007).

En el caso de $O$ Globo, la cuestión de la corrupción era denunciada en términos más amplios, ya que se acusaba al PT, pero también a la clase política en su conjunto. El periódico encuadraba la elección en términos morales, al indicar que:

En uno de los peores momentos de su historia reciente, el Congreso tiene una oportunidad preciosa para demostrar que el espíritu público todavía se cultiva en la Casa como un valor por encima del corporativismo y el clientelismo.

El elector debe también contribuir a perfeccionar el Poder Legislativo. Estrictamente hablando, él es el único capaz de purificar el Congreso y

DADOS - Revista de Ciências Sociais, Rio de Janeiro, vol. 60, n² 2, 2017 
Ariel Goldstein

las casas legislativas en general con el arma más simple y eficaz de la democracia: el voto. Cada uno de estos escándalos tiene un fuerte contenido pedagógico a ser metabolizado por los votantes para que en las próximas elecciones hagan una buena selección de candidatos ${ }^{61}$.

Se señalaba que la votación debería servir como una oportunidad para el castigo que debería ejercer la ciudadanía hacia los políticos corruptos. El periódico carioca exigía del electorado un "voto útil", indicando que "felizmente, la crisis ética coincide con las elecciones. Hay, por lo tanto, una posibilidad concreta de que la sociedad actúe para, con el voto, ayudar en la limpieza de la administración pública" ${ }^{\prime 62}$. Se pretendía así situar a la cuestión moral como la temática más importante de la elección y, en este aspecto, la condena moral que se esbozaba presentaba similitudes con el período de 1953 que hemos analizado en el apartado anterior, cuando ambos periódicos llamaban a excluir de la política a los corruptos. A la vez, el principal culpado de esta crisis moral sería el PT, si bien las acusaciones no serían únicamente realizadas hacia este partido:

\footnotetext{
El patrimonio ético del PT fue dilapidado. Tanto es así que el candidato Lula se desdobla para mantener distancia del partido que fundó: el rojo fue retirado de la campaña, substituido por el azul (...)

Intentar socializar la culpa del PT no es la mejor manera de mejorar las instituciones políticas. Así como supeditar la purificación de la vida parlamentaria a una amplia reforma política, que necesita ser debatida minuciosamente, sin prisas, no es más que la mitad de la verdad ${ }^{63}$.
}

Existía una intensa pretensión de ambos medios en sus titulares y columnas de centrar la agenda en torno a la corrupción, envolviendo en los acontecimientos a la dirigencia del PT. Así, se procuraba subordinar la agenda de la campaña electoral a una distinción entre "honestos" y "corruptos", excluyendo otras temáticas de la misma y desacreditando al PT como un partido destruido por la corrupción.

A finales de la campaña de 2006 estos periódicos tuvieron un importante papel al divulgar el descubrimiento de un dinero para un supuesto dossier que militantes petistas pretenderían adquirir para perjudicar al candidato tucano al gobierno paulista, José Serra. Este acontecimiento centraría en forma definitiva en torno a la corrupción la agenda de la campaña. En este sentido, O ESP acusaba al gobierno de esconder antes de las elecciones los datos del dossier, poniendo al Estado y las instituciones al servicio del proyecto reelectoral ${ }^{64}$. A su vez, 
titulaba que el "El presidente del PT sabía del encuentro en el que fue ofrecido el dossier contra Serra" (20/9/2006), para involucrar a las autoridades del partido en este escándalo.

En el caso de $O$ Globo, la aparición del tema del dossier marcaría un giro en su cobertura. Los columnistas del periódico, como Tereza Cruvinel, señalaban que la aparición del mismo transformaba en impredecible el rumbo de una elección donde hasta el momento Lula era el favorito ${ }^{65}$. Por su parte, O Globo centraba sus acusaciones sobre este nuevo escándalo y lo vinculaba con el mensalão y otras denuncias contra el partido. La aparición del "dossier" sobre el cierre de la campaña electoral de la primera vuelta implicaría que el periódico carioca, que había sostenido cierto equilibrio hasta el momento, comenzara a centrar su agenda en torno a la cuestión de la "corrupción petista". En este sentido, destacaba que

Detrás de esa delincuencia pública, habría una ética capciosa por la cual todo es válido en nombre del bien del pueblo, "ideología" que acaba de ser sorprendentemente adoptada por algunos artistas e intelectuales. El caso actual del dossier parece revelar algo aún más grave: la aparición de un bandidaje sindical, personas con largo kilometraje en los embates del $\mathrm{ABC}$ paulista, para quienes mantenerse en el poder es razón suficiente para justificar cualquier crimen. Hasta contra las instituciones ${ }^{66}$.

El periódico de Rio de Janeiro sostendría, vinculando al PT con la "delincuencia sindical", que habría inoculado en el partido el "virus de la delincuencia" ${ }^{\prime 67}$. Esta aseveración se producía al sostener que existiría una "ética capciosa" que justificaba las liviandades morales en nombre del "bien del pueblo", de este modo estigmatizando la pertenencia de izquierda de esta organización.

Es notorio como en O Globo el estallido del escándalo del dossier implicaría un cambio, donde el periódico pasaría a señalar al PT como un "partido de delincuentes", y a colocar sus denuncias en torno a la corrupción como eje de sus encuadres sobre la campaña. Esto tendría relevancia, considerando que sería realizado en el tramo final y más importante de la disputa electoral.

Sin embargo, en $O$ Globo, a pesar de la cobertura intensamente crítica frente al PT en este último tramo de la campaña, se permitiría la expre-

DADOS - Revista de Ciências Sociais, Rio de Janeiro, vol. 60, n’ 2, 2017 
sión de voces disidentes con la línea editorial del periódico, denunciando maniobras de desestabilización contra el gobierno ${ }^{68}$.

Durante este apartado, hemos visto como ambos periódicos irían produciendo una estigmatización progresiva del PT, lo cual se acentuaría con la emergencia del mensalão. A comienzos del mandato $O E S P$ y $O$ Globo manifestarían las acusaciones hacia esta organización por colonizar la máquina del Estado con militantes petistas, el denominado aparelhamento.

Con el surgimiento del mensalão, O ESP sostendría que éste escándalo sería el resultado de la transformación del PT en un mero proyecto de poder, demostrando el fracaso de un partido autoritario y corrupto. Así, el mensalão sería instrumentado por el matutino paulista para invalidar la posibilidad de que un gobierno de izquierda administre el país, indicando que se habrían terminado las perspectivas de este partido.

En O Globo, las críticas al PT estarían presentes en términos similares, pero éste asignaría como principal causa de la crisis a la existencia desmedida de cargos políticos, exigiendo una modernización del Estado y una reforma política. Frente a este escándalo político, O Globo propondría soluciones, a la vez que pretendía responsabilizar por el mismo al conjunto de la clase política. Esto lo acercaba a la invocación de una "cruzada moral" en los términos en los cuales hemos visto que enmarcarían la cuestión los periódicos en los años 1950.

Durante el período electoral de 2006, ambos periódicos encuadrarían la elección en términos morales, con el propósito de que la temática de la corrupción -especialmente a partir de la aparición del mencionado dossier contra Serra- fuera el tema más debatido, pretendiendo involucrar al partido en los escándalos para afectar su imagen. De este modo, nuevamente verificamos que estos periódicos pretendían subordinar la agenda pública a la distinción entre "honestos" y "corruptos".

\section{CONCLUSIÓN: LA MORALIZACIÓN DE LA POLÍTICA COMO ESTRATEGIA DE LA PRENSA}

Autores como Waisbord (2000) y Porto (2012) han destacado el proceso de modernización y profesionalización por el cual ha pasado la prensa brasileña desde la transición democrática. A su vez, el primer autor ha señalado que la misma se ajusta al rol de "perro guardián" propio de 
contextos pos-dictatoriales, el cual ha supuesto la adopción de un patrón periodístico más distante y crítico hacia los poderes gubernamentales, investigando a modo de "monitoreo ciudadano" las violaciones a la ética pública de políticos y funcionarios.

Sin embargo, este artículo arroja luz sobre las continuidades de la prensa en su visión unilateral en ambos períodos, representando visiones anti-pluralistas que la vinculan más de lo que ésta quisiera con las oligarquías autoritarias que han dominado el país históricamente. En este marco, la comparación de la actuación política de estos medios de prensa a lo largo de estos períodos lejanos en el tiempo, pero que presentan similitudes, nos ha permitido comprender su comportamiento frente a dos procesos protagonizados por líderes reformistas de alta popularidad.

Tanto en la coyuntura de 1953-1954 como en la que se desarrollaría entre el escándalo del mensalão en 2005 hasta la elección presidencial de 2006, los encuadres sobre la temática de la corrupción serían impulsados por ambos periódicos. A nuestro entender, esto no era solamente el resultado de la aparición pública de escándalos de corrupción, sino que evidenciaba una estrategia adoptada por estos medios de prensa como actores frente a estos presidentes. La misma tenía como propósito disputar la construcción de la agenda frente a estos mandatarios de alta popularidad para pautar la misma de un modo conveniente a sus intereses.

De este modo, la prensa adoptaría durante estos períodos una estrategia para disputar la construcción de la agenda pública frente a mandatarios cuyas definiciones contaban con un alto respaldo popular. La moralización de la política, que suponía la reducción de los asuntos públicos a la esfera de lo moral (Rubim, 2007), sería un recurso desplegado por los medios de prensa para recobrar protagonismo en la definición de la agenda. En este sentido, la búsqueda de subordinar el litigio de la política a la esfera de lo moral se revelaría como un recurso reiterado de la prensa en ambos períodos para incrementar su audiencia y sus posibilidades de pautar la agenda frente a mandatarios que contaban con una alta popularidad.

Estos medios de prensa, en función de su pretensión de naturalizar el orden político, buscaban excluir del debate público a la cuestión de la desigualdad, situada en la agenda por estos gobiernos. De este modo, la colonización de la política por el discurso moralista, regido por la

DADOS - Revista de Ciências Sociais, Rio de Janeiro, vol. 60, nº 2, 2017 


\section{Ariel Goldstein}

distinción entre "honestos" y "corruptos", se tornaba un recurso para excluir a la cuestión de la desigualdad de la agenda pública. Aclaramos que esto no significa que la colocación de la temática de la corrupción no fuera importante como un modo de fiscalización de la prensa frente al poder político. Sin embargo, la modalidad a partir de la cual la prensa lo ejerció frente a estos dos gobiernos tenía el efecto de restringir las potencialidades de su accionar político en el marco de una sociedad desigual en la cual estos medios actuaban en defensa del orden existente.

El modo en que la corrupción era tratada durante ambos períodos tenía que ver con producir un vaciamiento que redujera el debate público a la distinción entre "honestos" y "corruptos", en un proceso tendiente a la producción de "escándalos políticos" (Thompson, 2000) que apelaba al sentido común con el propósito de producir indignación ciudadana ${ }^{69}$. De este modo, se vaciaba de contenido el debate público, se restaba importancia al tema de la desigualdad en el país, así como se ocultaban el carácter sistémico y los orígenes históricos de la corrupción brasileña como apropiación originaria de las clases dominantes. Pocos años después, durante el segundo mandato de Dilma Rousseff (2014-2016), se evidenciaría nuevamente cuán efectiva resultaba para la prensa brasileña esta estrategia de apelar a la moralización para despertar una "indignación ciudadana" que acrecentara la crisis política de un gobierno reformista.

El análisis de estos dos períodos ha resultado relevante para entender la estrategia de estos medios de prensa frente a dos líderes populares, pues a partir de entonces, con la condensación que producirían, la política quedaría subordinada a la moral, restringiéndose las posibilidades de estos mandatarios de introducir la cuestión de la desigualdad en la agenda pública. De este modo, la estrategia de moralización de la política se revelaba como una condición para la naturalización del orden social por parte de estos medios de prensa, revelando su convergencia para la preservación del orden existente.

En tanto la prensa brasileña que hemos analizado se revela como un factor para la conservación del orden político y social, las "cruzadas morales" constituyen un elemento imprescindible para la producción de su naturalización. Al influenciar la construcción de una agenda centrada en cuestiones morales, se evitarían discusiones sobre la desigual- 
dad. Así, la estrategia de moralización de la política se revelaría como una condición para la naturalización del orden social en el país.

(Recebido para publicação em julho de 2015) (Reapresentado em maio de 2016 e janeiro de 2017)

(Aprovado para publicação em abril de 2017) 
Ariel Goldstein

\section{NOTAS}

1. Los hallazgos que aquí presentamos están vinculados a una reformulación de nuestro trabajo de tesis doctoral, "Prensa tradicional y liderazgos populares en Brasil: una comparación entre el segundo gobierno de Getúlio Vargas y el primer gobierno de Lula da Silva".

2. Durante esta segunda coyuntura, considerando la saturación teórica de los encuadres analizados en el período 20/05/1953 y 16/12/1953, así como el receso de fin de año que reduce la actividad política entre diciembre y enero, hemos definido considerar el período 17 / 12/1953 a 31/01/1954 sólo en forma exploratoria, recuperando los criterios de clasificación y análisis sistemático recién desde 01/02/1954 a 22/02/1954, que abarca el "Manifiesto de los Coroneles", el cual llevaría a la renuncia del Ministro de Trabajo, João Goulart.

3. Los tres períodos de análisis durante el primer gobierno de Lula abarcaron 573 días. Durante el período de Vargas, la selección de 426 días representa el 74\% de los días correspondientes al período de Lula, que son 573 . Este $16 \%$ más de editoriales que abarcamos para el período de Lula se justifica porque este último presidente llegó al fin de su mandato, a diferencia del de Vargas, cuyo mandato fue interrumpido por su suicidio. Esta diferencia supone que el primer gobierno de Lula tuvo 1460 días, es decir, un 11\% más que el de Vargas (1301 días).

4. Una diferencia relevante entre ambos períodos reside en los avances tecnológicos que inciden en la circulación de la información. En este sentido, Aguiar (2004) señala que en comparación con los días actuales, los años '50 en Brasil constituían la "edad de piedra", ya que no existían ni el fax ni las computadoras. En este sentido, destaca que una comunicación telefónica entre Río y San Pablo llevaba horas para completarse. Según el autor, en aquél entonces, los acontecimientos eran conocidos por la población que estaba fuera del eje Río de Janeiro-San Pablo sólo varios días después de sucedidos.

5. En tanto $O$ Globo era en la época el diario vespertino de mayor circulación (Lattman Weltman y Abreu, 1994), seleccionaremos las ediciones vespertinas de O Globo, en el caso de los días donde hubiera tanto una edición del periódico matutina como vespertina.

6. En la primera coyuntura, O ESP dedicaría sólo 2 editoriales a "la necesidad de introducir moralidad contra la corrupción". Ya en la segunda coyuntura, O ESP dedicaría 21 editoriales a denunciar "la inmoralidad y la corrupción de los políticos de São Paulo y la unión". A esto se sumarían 9 editoriales que denunciaban la "corrupción del gobierno". Notoriamente, vemos como el periódico situaría su agenda en torno a la temática de la corrupción a partir de la segunda coyuntura. Ligado a esto, 7 editoriales exigían un "candidato de la unidad moral para que no triunfe la demagogia en las elecciones intermedias de 1954". Además, 5 editoriales se dedicaban a denunciar que "el presidente y sus allegados estarían vinculados al caso Última Hora". En la última coyuntura, 10 editoriales tenían que ver con "extirpar a los Vargas para la restauración moral de Brasil" y 4 denunciarían la "corrupción gubernamental para los protegidos del Catete". A su vez, 7 exigían una "cruzada contra la inmoralidad de los políticos de San Pablo y Brasil". En O Globo existía sólo un editorial referido a esta temática durante la primera coyuntura, aunque abocado a indicar "la necesidad de combatir la corrupción policial". En la segunda coyuntura, 3 editoriales suponían 
que sería necesario ir contra "la inmoralidad y la corrupción". 1 señalaba que "el gobierno no debe intervenir en la prensa creando periódicos oficiales". 1 editorial sostenía que "un grupo aventurero (Wainer) ha llevado el país a la degradación moral". En la tercera coyuntura habría 1 editorial que señalaba que "Vargas lleva el país a la disolución moral".

7. "La defensa del honor nacional", 11/11/1953, O ESP y "El castigo de los corruptores", 26/11/1953, O ESP.

8. El caso “Última Hora” consistía en un préstamo facilitado por el gobierno de Getúlio Vargas al periodista Samuel Wainer para la creación de un medio pro-gobierno, lo que estaría prohibido ya que la constitución no admitía la propiedad de medios a extranjeros, lo que era el caso de Wainer.

9. "La palabra oficial", 30/05/1953, O ESP.

10. "Diluvio de escándalos", 31/05/1953, O ESP.

11. "Vuelta a la seriedad", 02/06/1953, O ESP.

12. "El fondo partidario", 06/09/1953, O ESP.

13. "El problema de la sucesión", 13/10/1953, O ESP.

14. Por ejemplo en esta noticia de la página 2 de O Globo, 03/10/1953.

15. Sección "El Momento Político", 03/07/1953, O ESP.

16. "El pueblo y el gobierno", 15/07/1953, O ESP.

17. Sección "El Momento Político", 15/07/1953, O ESP.

18. Rafael Correia de Oliveira, en columna titulada "Cruzada contra la corrupción" en la sección "El Momento Político", 26/07/1953, O ESP.

19. "El Banco de Brasil y la Prensa", 28/07/1953, O ESP.

20. "Los responsables por el escándalo bancario", 22/08/1953, O ESP.

21. "Los financiamientos de favor", 10/9/1953, O ESP.

22. "El poderío financiero del presidente de la Republica", 02/09/1953, O ESP.

23. "Guerra total contra la infamia", 13/09/1953, O ESP.

24. "Concurso de calamidades", 22/09/1953, O ESP.

25. "Símbolo de la corrupción de una época", 05/11/1953, O Globo.

26. "El gran papel del parlamento", 03/12/1953, O Globo.

27. "El proceso contra el presidente", 05/06/1954, O ESP.

28. "Las razones de la política", 12/06/1954, O ESP.

29. Según la Constitución de 1946, el mandato presidencial duraba 5 años. De los 1825 días que preveía el mandato, Vargas gobernaría durante 1301, ya que el mismo se vería interrumpido por su suicidio.

30. "Nuestro deber cívico", 01/06/1954, O ESP.

31. "La lección de Rio Grande", 20/07/1954, O Globo.

32. Durante este período, en la primera coyuntura, en O ESP 6 editoriales se referían al "aparelhamento del Estado por el PT", 4 a "parlamentarios ideológicos vs. pragmáti$\cos ^{\prime \prime}$ y 2 al "autoritarismo antidemocrático del partido". Durante la segunda coyuntura, un encuadre fundamental tenía que ver con 39 editoriales donde el PT era señalado como "de proyecto político a proyecto de poder". 7 editoriales adjudicaban la crisis al "aparelhamento del Estado del PT". Durante la tercera coyuntura, habría 25

DADOS - Revista de Ciências Sociais, Rio de Janeiro, vol. 60, nº 2, 2017 


\section{Ariel Goldstein}

editoriales dedicados a la denuncia del paso del PT "de proyecto político a proyecto de poder", así como 4 a denunciar la "corrupción sistémica" del partido. En el caso de O Globo, durante la primera coyuntura manifestaría su apoyo a los "pragmáticos" contra los "radicales del PT" en 5 editoriales. 3 editoriales eran críticos de la selección de funcionarios por "criterios partidarios" en lugar de "técnicos". En la coyuntura del mensalão, 7 señalaban que "el PT debe investigar la corrupción, procurar que aparezcan los responsables". Un encuadre fundamental eran 18 editoriales que sostenían que la crisis era una oportunidad para modernizar el Estado, reduciendo los cargos políticos, así como podía serlo para una reforma política. 5 atribuían la emergencia de la crisis al aparelhamento del Estado. 6 exigían que el mensalão debía ser investigado y no tapado por un acuerdo político, y 4 exigían que debía investigarse sin impedimentos a todos los políticos hasta el final. Además, 3 editoriales señalaban que el mensalão sería el resultado del proyecto de poder del PT, y 2 que el PT habría perdido su ética, mostrando prácticas atrasadas. En la última coyuntura, 2 denunciaban que el elector debía expulsar de la política a los corruptos, así como 6 denunciaban que los políticos corruptos debían ser suspendidos de la política; y 4 denunciaban que el PT habría producido corrupción y delincuencia.

33. La crisis política del "mensalão" surgió a partir de las tensiones que se produjeron al interior de la heterogénea alianza que el PT había compuesto a nivel parlamentario para garantizar la "gobernabilidad" (PL, PPS, PTB y PDT). En mayo de 2005, la Revista Veja publicó la transcripción de un video donde se acusaba al diputado de la coalición gubernamental Roberto Jefferson del Partido Laborista Brasileño (PTB), de estar detrás del desvío de dinero en la empresa pública de Correos. El entonces diputado, que habría intuido que no recibiría en este contexto apoyo del Palacio del Planalto (Pilagallo, 2012), decidió en consecuencia realizar una serie de denuncias que tuvieron un efecto explosivo. En una entrevista el 6 de junio a la Folha de S. Paulo, acusó al PT de estar pagando una mensualidad a los parlamentarios de la base aliada a cambio de apoyo al gobierno de Lula en el Congreso. La conmoción que la denuncia de estos escándalos produjo en la opinión pública tuvo por efecto: una importante erosión del capital político del gobierno, un incremento en la polarización entre el gobierno y la oposición, así como la apertura de varias Comisiones Parlamentarias de Investigación (CPI) encargadas de investigar los acontecimientos en el Congreso.

34. "Corporativismo", 20/07/2003, O Globo.

35. "Vuelta al pasado", 27/08/2003, O Globo.

36. Columna "Los compañeros ocupan la máquina”, 17/07/2003, O Globo.

37. "Los nombramientos apadrinados", 03/09/2003, O ESP.

38. "Reducir el Estado", 25/06/2005, O Globo.

39. "Evitar el retroceso", 07/07/2005, O Globo.

40. "A qué punto llegaron", 26/05/2005, O ESP.

41. "Ética de mano pesada", 01/07/ 2005, O ESP.

42. O ESP titulaba el 18/09/2005: "Las cuentas muestran la fiesta del PT con el fondo partidario". Subtítulo: "Los recursos públicos fueron usados hasta para pagar los gastos del asesor preso con dólares en los calzones".

43. "Partido desacreditado", 10/06/2005, O ESP.

44. "Victoria de la nación", 14/08/2005, O Globo. 
45. "Paciencia, paciencia...", 27/08/2005, O ESP.

46. "Corrupción organizada", 07/06/2005, O ESP.

47. "El presidente cambia de rumbo", 01/07/2005, O ESP.

48. "La primera renuncia", 03/08/2005, O ESP.

49. "Pizza en la dirección del PT", 09/08/2005, O ESP.

50. "Lo que es mejor para la economía", 21/08/2005, O ESP.

51. "Para comprender la crisis", 29/08/2005, O ESP.

52. "Paciencia, paciencia...", 27/08/2005, O ESP.

53. "Soy, ipero quién no es?", 16/06/2005, O ESP.

54. "La verdad ya llegó", 20/10/2005, O ESP.

55. "El sofá de la sala", 26/05/2005, O ESP.

56. "Aprovechar el momento", 10/06/2005, O ESP.

57. “La verdad de los hechos", 05/10/2005, O Globo.

58. "Organizaciones criminales", 01/05/2006, O ESP.

59. "De una CPI para otra", 22/06/2006, O ESP.

60. “El 'modus operandi' de la reelección”, 12/09/2006, O ESP.

61. "Esopo explica", 21/09/2006, O ESP.

62. "Pedagogía política", 11/05/2006, O Globo.

63. "Voto útil", 08/08/2006, O Globo.

64. "Media verdad", 18/08/2006, O Globo.

65. "Escándalo de la distracción del dossier", 30/09/2006, O ESP.

66. Columna, "Crimen y castigo", 20/09/2006, O Globo.

67. "Tropa de choque", 20/09/2006, O Globo.

68. "Encrucijada", 28/09/2006, O Globo.

69. Columna de Valter Pomar, "Mala hierba y trigo", 28/09/2006, O Globo.

70. Desde el triunfo de Janio Quadros en las elecciones presidenciales de 1960 con el lema de la escoba para barrer la corrupción, la moralización ha llevado en distintos períodos históricos a una clausura del debate público sobre la desigualdad en el país. 


\section{Ariel Goldstein}

\section{BIBLIOGRAFÍA}

ABREU, Alzira; LATTMAN-WELTMAN, Fernando. (1994), "Fechando o Cerco: A Imprensa e a Crise de Agosto de 1954", en A. de C. Gomes (comp.), Vargas e a Crise dos Anos 50. Rio de Janeiro, Relume Dumará, pp. 23-59.

AGUIAR, Ronaldo Conde. (2004), Vitória na Derrota: A Morte de Getúlio Vargas. Rio de Janeiro, Casa da Palavra.

ALDÉ, Alessandra; MENDES, Gabriel; FIGUEIREDO, Marcus. (2007), “Imprensa e Eleições Presidenciais: Natureza e Consequências da Cobertura das Eleições de 2002 e 2006", en V. Lima (org.), A Mídia nas Eleições de 2006. São Paulo, Fundação Perseu Abramo.

ANSART, Pierre. (1983), Ideología, Conflictos y Poder. Puebla, Premiá.

AZEVEDO, Fernando. (2009), “A Imprensa Brasileira e o PT: Um Balanço das Coberturas das Eleições Presidenciais (1989-2006)". ECO-Pós, vol. 12, no 3, pp. 48-65.

BARTHES, Roland. (2004), Mitologías. Buenos Aires, Siglo XXI.

BIROLI, Flavia. (2004), “Jornalismo, Democracia e Golpe: A Crise de 1955 nas Páginas do Correio da Manhã e de O Estado de S. Paulo". Revista de Sociologia e Política, vol. 22, pp. 87-99.

CARVALHO, Aloysio. (2012), O Caso Última Hora e o Cerco da Imprensa ao Governo Vargas. Niterói, RJ, Editora da UFF.

CAPELATO, Maria Helena. (2013), "Mídia e Populismo/Populismo e Mídia". Revista Contracampo, vol. 28, no 3, pp. 52-72.

ENTMAN, Robert. (1993), "Framing: Toward Clarification of a Fractured Paradigm". Journal of Communication, vol. 41, no 4, pp. 51-58.

FAUSTO, Boris. (2003), Historia Concisa de Brasil. Buenos Aires, FCE.

FONTES, Paulo. (2013), “Trabalhadores e Associativismo Urbano no Governo Jânio Quadros em São Paulo (1953-1954)”. Revista Brasileira de História, vol. 33, no 66, pp. 71-94.

GAMSON, William; MODIGLIANI, Andre. (1989), “Media Discourse and Public Opinion on Nuclear Power: A Constructionist Approach". American Journal of Sociology, vol. 95, no 1, pp. 1-37.

GOULART RIBEIRO, Ana Paula. (2007), Imprensa e História no Rio de Janeiro dos Anos 1950. Rio de Janeiro, E-Papers.

KOTSCHO, Ricardo. (2006), Do Golpe ao Planalto: Uma Vida de Repórter. São Paulo, Companhia das Letras.

KUCINSKI, Bernardo. (1998), A Síndrome da Antena Parabólica. São Paulo, Fundação Perseu Abramo.

. (2007), “O Antilulismo na Campanha de 2006 e suas Raízes", en V. Lima (org.), A Mídia nas Eleições de 2006. São Paulo, Fundação Perseu Abramo.

LIMA, Venício. (2006), Mídia: Crise Política e Poder no Brasil. São Paulo, Editora Fundação Perseu Abramo. 
(2007), “Eleições Presidenciais de 2006: Vitória de Lula Coloca Mídia em Questão", en Se nos Rompió el Amor. Elecciones y Medios de Comunicación: América Latina2006, Documento de Trabajo No. 3. Centro de Competencia en Comunicación para América Latina.

MIGUEL, Luis; COUTINHO, Aline de Almeida. (2007), “A Crise e suas Fronteiras: Oito Meses de 'Mensalão' nos Editoriais dos Jornais". Opinião Pública, vol. 13, no 1, pp 97-123.

MUNDIM, Pedro. (2010), Imprensa e Voto nas Eleições Presidenciais Brasileiras de 2002 e 2006. Tesis Doctoral, Instituto Universitário de Pesquisas de Rio de Janeiro (IUPERJ).

NETO, Lira. (2014), Getúlio. Da Volta pela Consagração Popular ao Suicídio (1945-1954). São Paulo, Companhia das Letras.

PILAGALLO, Oscar. (2012), Historia da Imprensa Paulista: Jornalismo e Poder de D. Pedro a Dilma. São Paulo, Três Estrelas.

PORTO, Mauro. (2002), Enquadramentos da Mídia e Política. Trabajo presentado en el XXVI Encontro Anual da Associação Nacional de Pós-Graduação e Pesquisa em Ciências Sociais (Anpocs), Caxambu/MG, 22-26 de octubre.

. (2012), Media Power and Democratization in Brazil: TV Globo and the Dilemmas of Political Accountability. New York/London, Routledge.

RUBIM, Antonio Albino Canelas. (2009), “Mídia, Política e Eleições de 2006”. Teoria e Debate, vol. 20, no 69, pp. 38-42.

; COLLING, Leandro. (2006), "Política, Cultura e Cobertura Jornalística das Eleições Presidenciais de 2006", en J. Goulart (comp.), Mídia e Democracia. São Paulo, Annablume.

THOMPSON, John. (2000), Political Scandal: Power and Visibility in the Media Age. Oxford, Polity Press.

VERÓN, Eliseo. (1987), “La Palabra Adversativa”, en El Discurso Político. Buenos Aires, Hachette, Buenos Aires.

WAISBORD, Silvio. (2000), Watchdog Journalism in South America: News, Accountability and Democracy. New York, Columbia University Press.

\section{Archivos consultados}

Archivo de O Estado de S. Paulo, disponible en internet.

Archivo de $O$ Globo, disponible en internet.

Archivo de Discursos Presidenciales, Presidencia de la República, disponible en internet.

DADOS - Revista de Ciências Sociais, Rio de Janeiro, vol. 60, nº 2, 2017 


\section{Ariel Goldstein}

RESUMO

A Imprensa Brasileira e suas "Cruzadas Morais": Análise dos Casos do Segundo Governo de Getúlio Vargas e do Primeiro Governo de Lula da Silva

A partir da análise de matérias, editoriais e outras seções dos jornais $O$ Estado de São Paulo e O Globo, durante o segundo governo de Getúlio Vargas e o primeiro governo Lula, este artigo explora as características da chamada "moralização da política", adotada pela imprensa em ambos os períodos. Neste sentido, defende-se que a estratégia de submeter os assuntos públicos à distinção entre "honestos" e "corruptos" tinha o intuito de esvaziar o debate público, com ênfase em acusações de corrupção voltadas para os governos e na ocultação da apropriação histórica das classes dominantes. Assim sendo, a imprensa contribuiria para a naturalização da ordem social no país. Por sua vez, com essa postura editorial, ambos os jornais viriam a favorecer nestes períodos a construção de cenários de intensas crises políticas que permearam esses governos.

Palavras-chave: Lula; Vargas; imprensa; Brasil; política

\section{ABSTRACT}

The Brazilian Press and its "Moral Crusades": An Analysis of Several Cases under President Getúlio Vargas' Second Term and President Lula da Silva's First Term

By means of an analysis of the contexts and debates in editorials and other sections of $O$ Estado de S. Paulo and O Globo newspapers during Getúlio Vargas' second presidential term and Lula da Silva's first presidential term, the following article explores the characteristics of what it terms the "moralization of politics" adopted by the press during both periods. In this sense, it is argued that the strategy of colonizing public matters with the distinction between "honest" and "corrupt" was aimed at silencing public debate, focusing the accusations of corruption on governments and concealing the historical appropriation of the ruling classes. The press was therefore complicit in naturalizing the social order in Brazil, with the two newspapers also favoring the shaping of political crisis scenarios so significant as to have rocked these governments.

Keywords: Lula; Vargas; press; Brazil; politics 
RÉSUMÉ

La Presse Brésilienne et ses "Croisades Morales": Une Analyse des Cas du Second Mandat de Getúlio Vargas et du Premier de Lula da Silva

À partir de l'analyse de la ligne et des discours des éditoriaux et autres sections des quotidiens $O$ Estado de S. Paulo et $O$ Globo durant le second mandat de Getúlio Vargas et le premier de Lula da Silva, cet article explore les caractéristiques de la supposée "moralisation de la politique" prônée par la presse lors de ces deux périodes. En ce sens, on soutiendra que la stratégie de colonisation des affaires publiques par la distinction entre "honnêtes" et "corrompus" a eu pour objectif de vider le débat public de sa substance en centrant les accusations de corruption sur les gouvernements et en occultant l'appropriation historique des classes dominantes. La presse collaborerait ainsi à la naturalisation de l'ordre social en vigueur dans le pays. En même temps, cette ligne éditoriale favoriserait dans les deux quotidiens la construction du climat de crise politique qui a traversé les deux mandats en question.

Mots-clés: Lula; Vargas; presse; Brésil; politique

\section{RESUMEN}

La Prensa Brasileña y sus "Cruzadas Morales": Un Análisis de los Casos del Segundo Gobierno de Getúlio Vargas y el Primer Gobierno de Lula da Silva

A partir del análisis de los encuadres y discursos en los editoriales y otras secciones de los periódicos O Estado de S. Paulo y O Globo durante el segundo gobierno de Getúlio Vargas y el primer gobierno de Lula da Silva, este artículo explora las características de lo que denomina como la "moralización de la política" adoptada por la prensa en ambos períodos. En este sentido, se sostiene que la estrategia de colonizar los asuntos públicos con la distinción entre "honestos" y "corruptos" tenía por fin vaciar el debate público, centrando las acusaciones de corrupción sobre los gobiernos y ocultado la apropiación histórica de las clases dominantes. De este modo, la prensa colaboraría para la naturalización del orden social en el país. A su vez, con estos encuadres, ambos periódicos favorecerían en estos períodos la construcción de escenarios de crisis políticas de intensidad que atravesarían estos gobiernos.

Palabras clave: Lula; Vargas; prensa; Brasil; política

DADOS - Revista de Ciências Sociais, Rio de Janeiro, vol. 60, n² 2, 2017 